See Article page 223.

\section{Commentary: All the tricks in the book for late-presenting dextro-transposition of the great arteries with total anomalous pulmonary venous drainage}

\author{
David S. Winlaw, MBBS, MD, FRACS
}

Late presenting total anomalous pulmonary venous drainage with transposition of the great arteries is an uncommon combination of lesions, and management of this complex in later life is an additional challenge. A satisfactory atrial communication and unobstructed venous drainage as described in this case presented by Mishra and colleagues ${ }^{1}$ allows for mixing with the development of generously proportioned venous structures. The application of a modified Senning-type atrial switch is an elegant solution, beautifully illustrated and narrated in this report.

The authors' comfort with the atrial switch procedure, no doubt reflecting the relatively common late presentation of dextro-transposition of the great arteries in the northwest of the Indian subcontinent, is evident in their video. The procedure is a master class in the creation of systemic and venous baffles. Key take-home messages include unroofing of the coronary sinus, removal of right atrial trabeculations before the creation of the systemic venous pathway, and the use of in situ pericardium in creation of the pulmonary venous channel. In this case, the latter includes drainage of an unroofed pulmonary venous confluence, addressing the anomalous venous drainage as well as achieving diversion of atrial flow. Such procedures have been performed in a number of cases, most of which have achieved a good outcome.

From Cardiothoracic Surgery, Heart Institute, Cincinnati Children's Hospital Medical Centre; and Department of Surgery, University of Cincinnati, Cincinnati, Ohio. Disclosures: The author reported no conflicts of interest.

The Journal policy requires editors and reviewers to disclose conflicts of interest and to decline handling or reviewing manuscripts for which they may have a conflict of interest. The editors and reviewers of this article have no conflicts of interest.

Received for publication Aug 18, 2020; revisions received Aug 18, 2020; accepted for publication Aug 21, 2020; available ahead of print Sept 2, 2020.

Address for reprints: David S. Winlaw, MBBS, MD, FRACS, Cardiothoracic Surgery, Heart Institute, Cincinnati Children's Hospital Medical Centre, 3333 Burnet Ave, MLC2013, Cincinnati, OH 45229-3026 (E-mail: david.winlaw@cchmc.org).

JTCVS Techniques 2020;4:230-1

2666-2507

Copyright $\odot 2020$ The Authors. Published by Elsevier Inc. on behalf of The American Association for Thoracic Surgery. This is an open access article under the CC BY-NCND license (http://creativecommons.org/licenses/by-nc-nd/4.0/).

https://doi.org/10.1016/j.xjtc.2020.08.052

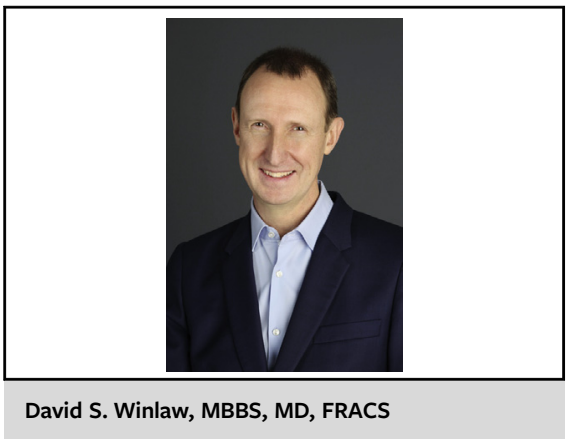

\section{CENTRAL MESSAGE \\ As the offering of cardiac surgery extends to include self-palliated CHD in later life, operations now uncommon in countries with well-resourced health systems are increasingly required.}

In some ways, the atrial switch is more straightforward when the pulmonary veins drain outside the atrial mass compared with normal anatomy, as the pulmonary venous drainage can be "collected" by the in situ pericardial pulmonary venous baffle. Intracardiac pulmonary venous drainage could be created in many of these cases but would require baffling around this newly created confluence to create the systemic venous pathways, an unnecessary and timeconsuming exercise.

As surgery for congenital heart disease becomes more accessible to all people of the world, there is an opportunity to translate learnings from that environment to the lowvolume requirement for atrial diversion as part of anatomic repair for corrected transposition. Abnormalities of cardiac position, left superior vena cavae to coronary sinus, and requirement for concomitant procedures often complicate this picture. ${ }^{2}$ Countries with developing medical infrastructure will be a reservoir of experience and innovation in procedures such as this. ${ }^{3}$

The longer-term outcome of patients with a systemic right ventricle remains concerning, ${ }^{4}$ but resolution of hypoxia and improvements in the efficiency of the circulation will be likely to dramatically improve the patient's ability to exercise, and there are no meaningful alternatives.

This report also serves to highlight India's role in the worldwide development of our specialty. India undertakes a high volume of congenital cardiac surgeries in numerous excellent centers, where complex work is now routinely performed and late presentation a 
common challenge. Simultaneously, migration increases the number of such patients in highly industrialized nations. The practice of our specialty is enhanced by the cross-border interchange of ideas and experience between practitioners.

\section{References}

1. Mishra A, Garg P, Agarwal V, Rana Y. Transposition of great arteries with total anomalous pulmonary venous connection: a modified Senning procedure for late presentation. J Thorac Cardiovasc Surg Tech. 2020;4: 223-6.

2. Barron DJ, Davies B. The atrial switch component of the double-switch procedure: management of venous anomalies and role of the superior cavopulmonary connection. Op Tech Thorac Cardiovasc Surg. 2013;18:190-203.

3. Hosny H, Sedky Y, Romeih S, Simry W, Afifi A, Elsawy A, et al. Revival and modification of the Mustard operation. J Thorac Cardiovasc Surg. 2019;159: 241-9.

4. Cuypers JAAE, Eindhoven JA, Slager MA, Opić P, Utens EM, Helbing WA, et al. The natural and unnatural history of the Mustard procedure: long-term outcome up to 40 years. Eur Heart J. 2014;35:1666-74. 